DrE/PC/89783--T4

$\mathrm{DOE} / \mathrm{PC} / 89783--\mathrm{T} 4$

DE92 011459

Quarterly Progress Report for the period 10/01/91 - 12/31/91

to the US Department of Energy

Project title:

Project number:

Principal Investigator:

\author{
"Fundamental Studies of Catalytic \\ Processing of Synthetic Liquids"
}

DE-FG22-89PC89783

Prof. Philip R. Watson

Department of Chemistry and Center

for Advanced Materials Research

Oregon State University

Gilbert Hall 153

Corvallis, OR 97331-4003

\title{
Date of report:
}

1/22/92

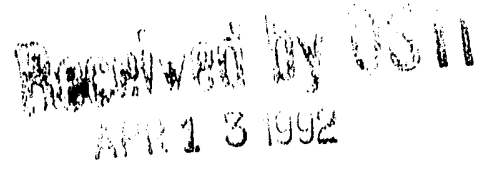

\section{DISCLAIMER} Government. Neither the United States Government nor any agency thereof, nor ans liability or responsiemployees, makes any warranty, express or implied, or assumes any legal tiability, apparatus, product, or bility for the accuracy, completeness, or usefulness of any information not infringe privately owned rights. Referprocess disclosed, or represents that its use would not inferes, or service by trade name, trademark, ence herein to any specific commercial product, process, or service by its endorsement, recommanufacturer, or otherwise does not necessarily constitute or imply inency thereof. The views mendation, or favoring by the United States Government or an at necessarily state or reflect those of the and opinions of authors expressed herey thereof. 


\section{Background}

This project revolves around understanding the fundamental processes involved in the catalytic removal of harmful oxygenated organics present in coal liquids. We are modelling the complex type of sulfided Mo catalyst proposed for these reactions with simple single crystal surfaces. These display a controlled range and number of reaction sites and can be extensively characterized by surface science techniques. We then investigate the reaction pathways for representative simple oxygenates upon these surfaces 2. Summary

Our previous work has shown that an important component of furan reactions on sulfided Mo surfaces are dehydrogenation reactions of adsorbed hydrocarbon fragments. The desorption of hydrogen occurs in several steps and is strongly influenced by the amounts of sulfur and carbon on the surface. In order to better understand this complex behavior during this quarter we have performed a complete comparison series of adsorption/desorption experiments for hydrocarbons and furan on sulfur covered $\mathrm{Mo}(110)$ surfaces. The work has focused on the interdependence of three variables: type of gas reacted, amount of gas dosed, and the level of sulfur precoverage on the Mo(110) surface. Auger electron spectroscopy (AES) and temperature programmed reaction spectroscopy (TPRS) were used to monitor gas phase products and post reaction surface residues.

On the clean $\mathrm{Mo}(110)$ surface, the same absolute molar amounts of furan and ethylene are adsorbed leading to similar amounts of hydrogen desorbed through dehydrogenation reactions, and twice as much residual carbon from furan. Both TPRS and AES data suggest that only $2 / 3$ as much propene adsorbs and reacts. The TPRS data also indicate that the dehydrogenation pathways for furan are of higher energy than those for the simple hydrocarbons. On sulfided Mo(110), the differences between furan and the hydrocarbons are much less pronounced.

\section{Progress}

a) Experimental details:

The series of experiments fall into two sets. The first examined the effect of varying the gas dosage on the initially clean $\mathrm{Mo}(110)$ sample and the second used a saturation dose of each gas while varying the initial sulfur coverage on the sample. A typical experiment 
involves confirming sample cleanliness and predosing with sulfur if required. Then the gas of interest is leaked into the chamber via high precision valve; practical resolution for gas exposure using this equipment is $5 \times 10^{-3}$ Langmuirs. At this point the TPRS run is initiated $\left(0-400^{\circ} \mathrm{C}, 10^{\circ} / \mathrm{sec}\right.$.). Species monitored during the temperature ramp include dihydrogen and the parent molecule (or the principle cracking fragment of the parent). The latter provides a measure of how much, if any, of the dosed gas leaves the surface without decomposition. For hydrocarbons reacting over clean refractory metal surfaces extensive decomposition occurs; the $\mathrm{H}_{2}$ TPRS curve area is a good qualitative measure of the number of gas molecules reacting [1]. The other indicator of the extent of decomposition, is the amount of residual carbon on the surface of the sample [2], which can be measured by AES. This carbon residue is measured at two different points during the experiment, immediately after the TPRS run and after a further heating to $850^{\circ} \mathrm{C}$ (to ensure complete decomposition). Subsequent data analysis yields integrated $\mathrm{H}_{2}$ TPRS peak areas, $\mathrm{H}_{2}$ peak maxima locations, and relative carbon coverage post reaction.

b) Results:

Figure 1 shows plots of total integrated TPRS $\mathrm{H}_{2}$ peak areas versus initial gas dosage for furan, ethylene, and propene on clean $M o(110)$. The shape of the curves for low exposures are very similar (Figure 1b), and the amount of $\mathrm{H}_{2}$ evolved at saturation is similar for all three gases (Figure 1a). If total decomposition of the materials is sccurring by the end of the temperature ramp at $400^{\circ} \mathrm{C}$, then we would expect these areas to correlate with the amount of hydrogen available in the reactants. This correlation is approximately true for furan and ethylene, but the amount of hydrogen obtained from propene is only about $2 / 3$ of that expected from total decomposition (Table 1 ). This could arise from either less propene molecules adsorbing, or imply that similar numbers of furan and ethylene molecules react while only $2 / 3$ as many propene molecules decompose.

Figures 2 and 3 are analogous plots to Figure 1 which follows residual carbon deposits after heating to $400^{\circ} \mathrm{C}$ (Figure 2) or $850^{\circ} \mathrm{C}$ (Figure 3) as a function of gas dosage. Again the curves saturate at low exposures, but with differing amounts of surface carbon (see Table 1). The carbon residue is greatest for furan and is twice that from ethylene as would be expected if equal amounts of the two reactants had adsorbed. For propene the 
residual C AES signal is again about $2 / 3$ of that expected for a molar amount adsorbed similar to that for ethylene or propene. The AES and TPRS data is therefore consistent with propene adsorption being hindered relative to either ethylene or furan.

Despite the apparent similarities between furan and ethylene reactions on clean $\mathrm{Mo}(110)$, the dehydrogenation processes for ethylene are energetically different from those of furan. As Table 1 indicates, the peak maximum for the release of hydrogen from the surface during a TPRS run is $100 \mathrm{~K}$ higher for furan than for either hydrocarbon. Clearly, dehydrogenation of a hydrocarbon fragment from adsorbed furan is a higher energy process than the equivalent process for a simple hydrocarbon.

The second set of experiments held the gas dosages constant at a saturation value while varying the extent to which the $M o(110)$ is precovered with sulfur. Figure 4 shows the change in $\mathrm{H}_{2}$ production as the sulfur precoverage is increased. The area of the TPRS curves are quite similar for each gas. The carbon residue AES measurements at 400 or $850^{\circ} \mathrm{C}$ for sulfur-covered $\mathrm{Mo}(110)$ from all three gas reactions were essentially indistinguishable (Figures 5 and 6). The marked differences between furan and ethylene $\mathrm{H}_{2}$ TPRS areas and the much larger residual $\mathrm{C}$ present after furan adsorption on the clean surface are no longer apparent. The sulfur present on the surface appears to lower the amount of furan that will react. Both the TPRS and AES curves vary linearly with the amount of sulfur on the surface. This is consistent with an adsorption site blocking role for preadsorbed S. On $\mathrm{Mo}(100)$ sulfur is believed to cause little chemical modification of the surface; it mainly serves to physically block adsorption sites [1].

It is evident from this data is that a S/Mo AES peak ratio of 2.0 approaches the point at which gas reaction/absorption stops. A ratio of about 2.5 indicates 0.5 monolayers of sulfur using our equipment. With a sulfur coverage at or above 0.5 monolayers, no reaction is detectable by either TPRS or AES for all three gases. This implies that each of these gases requires two adjacent sites for decomposition since $0.5 \mathrm{ML}$ of sulfur blocks 1 out of every 2 sites.

\section{Future Work}

Research during the next quarter will concentrate on the establishing the surface coverage of carbon that occurs in furan adsorption via ethylene and $\mathrm{CO}$ adsorption 
experiments. When we have that information in hand we will use the hydrogen TDS data on sulfided and carbided surfaces that we have generaied here to illuminate the hydrogen evolution that occurs during furan reactions on these surfaces.

\section{References}

1. D.G. Kelly, Ph.D. Thesis, University of California, Berkeley, 1987.

2. J.T. Roberts and C.M. Friend, J. Amer. Chem. Soc., 1087204 (1986). 


\begin{tabular}{|c|c|c|c|c|}
\hline $\begin{array}{l}\text { 뫀 } \\
\text { 물 }\end{array}$ & 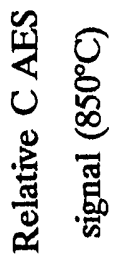 & 9 & $\exists$ & $\stackrel{\circ}{\text { i }}$ \\
\hline 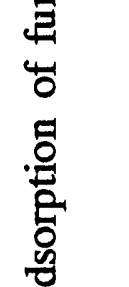 & 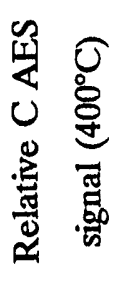 & $\stackrel{\infty}{-}$ & $\stackrel{\text { i }}{\text { in }}$ & $\grave{\wedge}$ \\
\hline 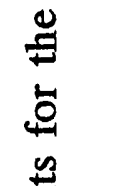 & 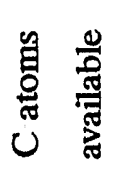 & $\stackrel{\sim}{\sim}$ & $\stackrel{0}{\dot{m}}$ & $\stackrel{\leftrightarrow}{+}$ \\
\hline 焉 & 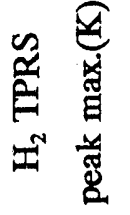 & ஜ্ & శ్ళ్ & ஜ \\
\hline 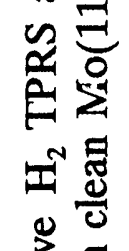 & 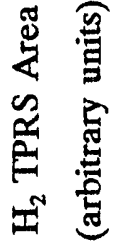 & $\sqrt{2}$ & $\stackrel{\sim}{\sim}$ & $\stackrel{m}{N}$ \\
\hline 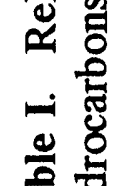 & 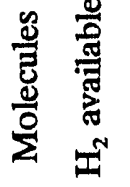 & 오 & ले & $\stackrel{\text { i }}{\text { in }}$ \\
\hline & 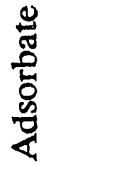 & 总 & $\begin{array}{l}\text { : } \\
\text { \& } \\
\text { \& }\end{array}$ & 㼂 \\
\hline
\end{tabular}




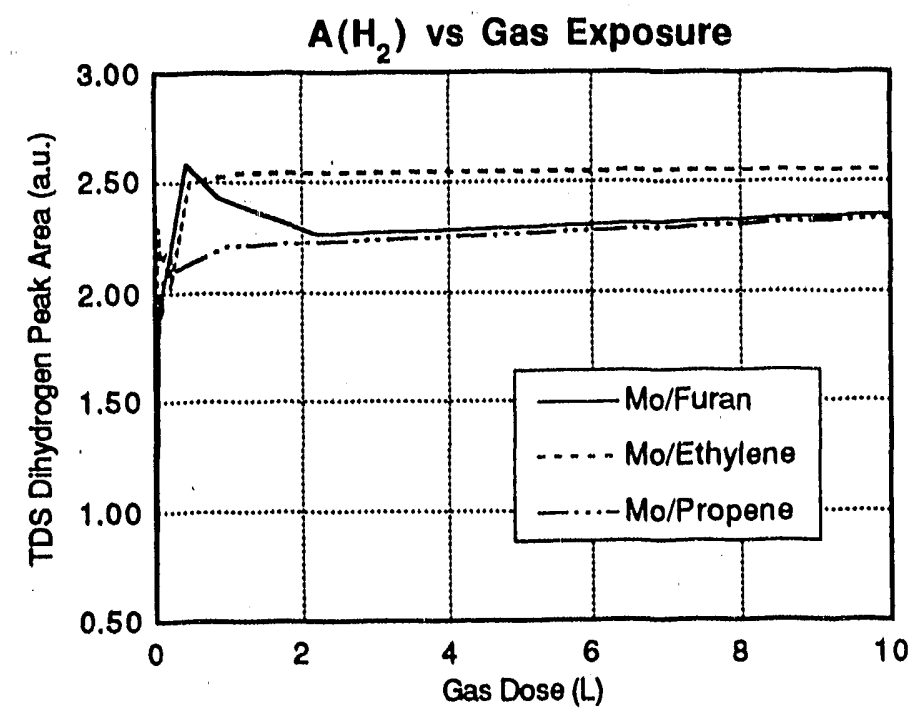

a)

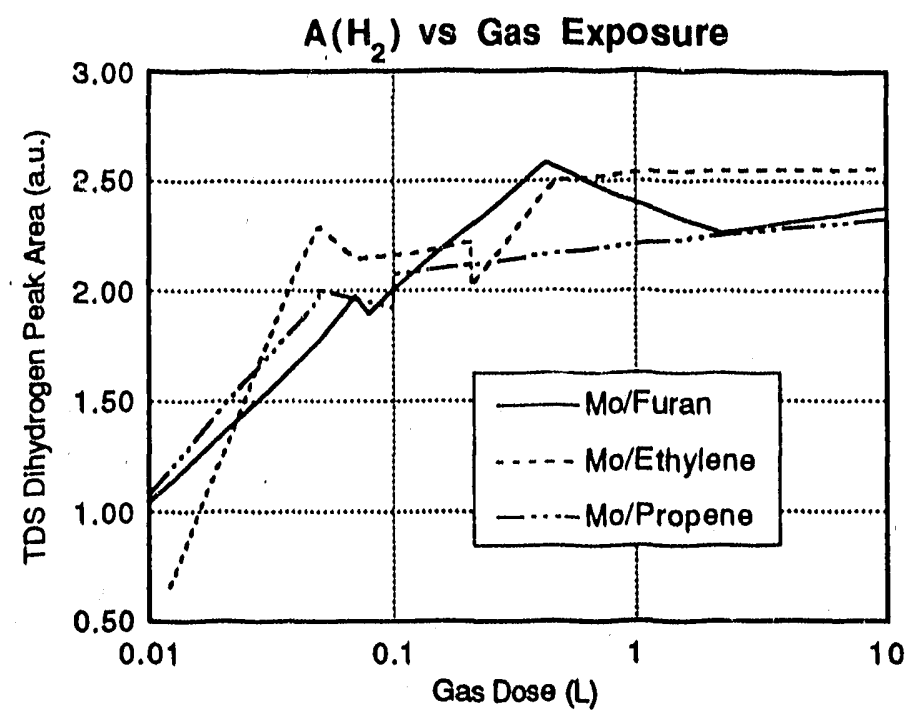

b)

Figure 1. Total $H_{2}$ TPRS areas from the adsorption of furan, ethylene and propene on Mo(110) a) for low doses and b) high doses

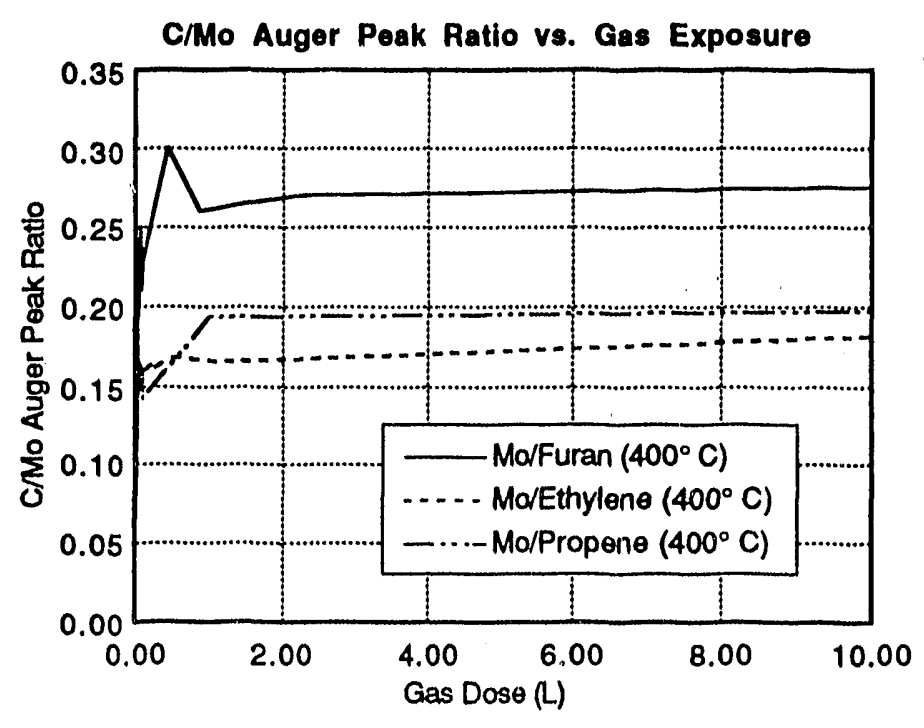

a)

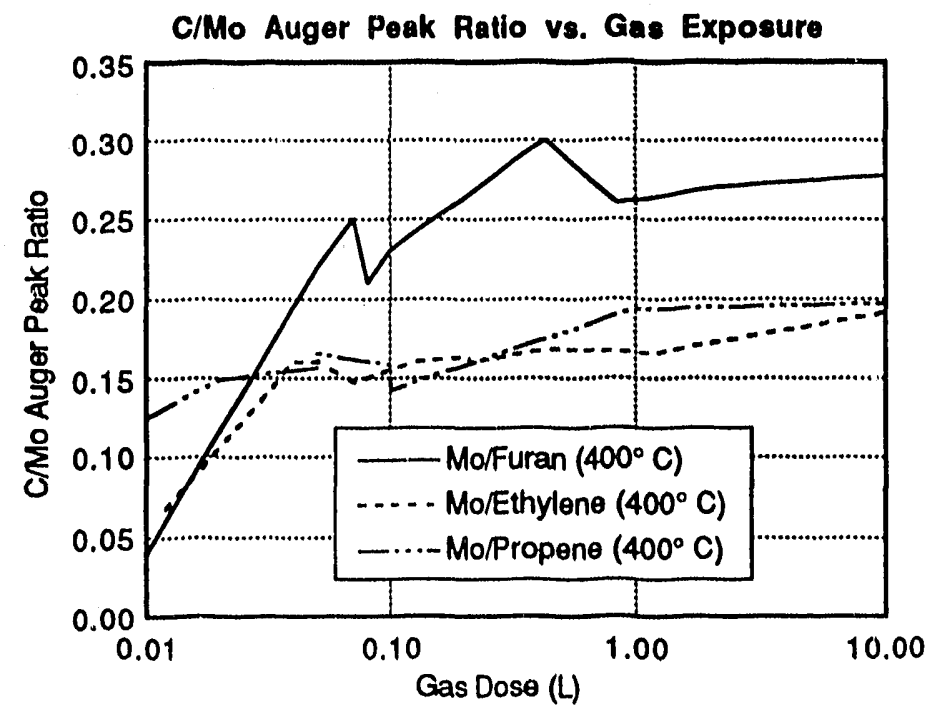

b)

Figure 2. C/MO AES ratio as a function of gas exposure for a) high exposures and b) low exposures (400C data) 


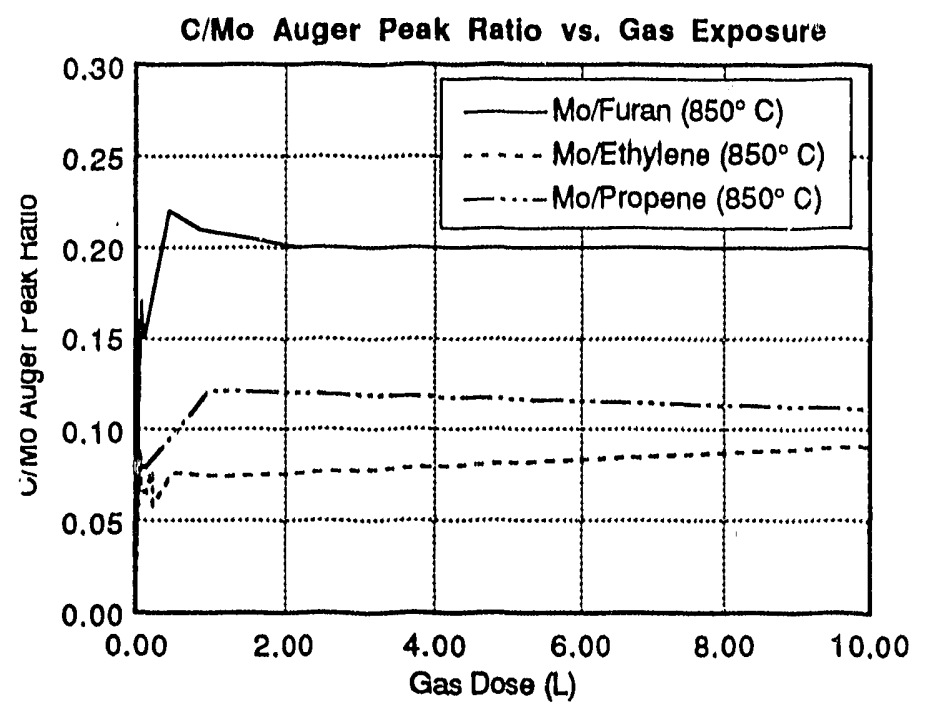

a)

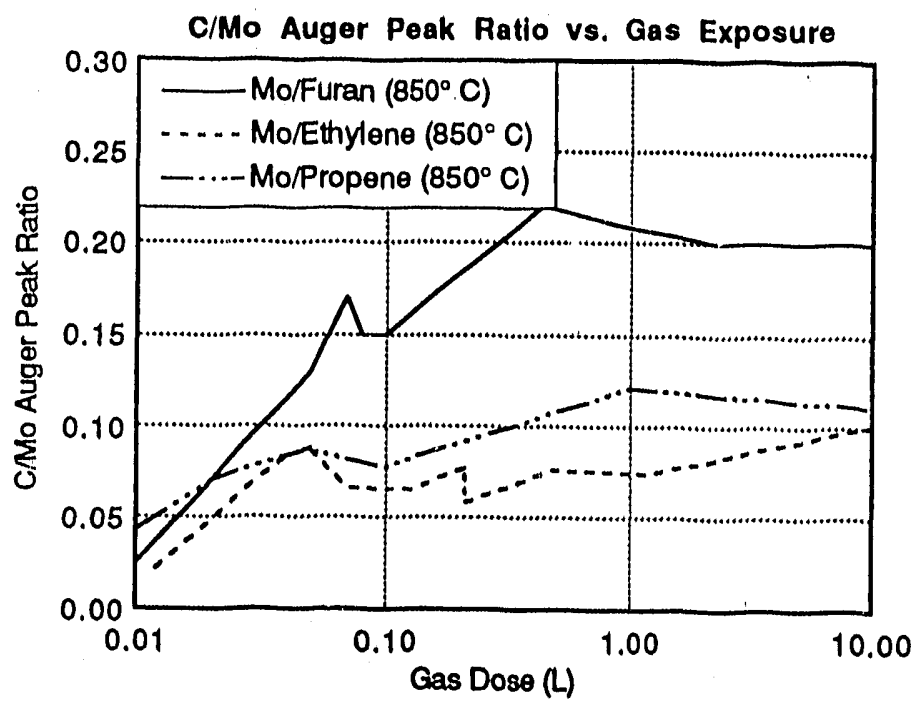

b)

Figure 3. C/MO AES ratio as a function of gas exposure for a) high doses and b) low doses (850C data)

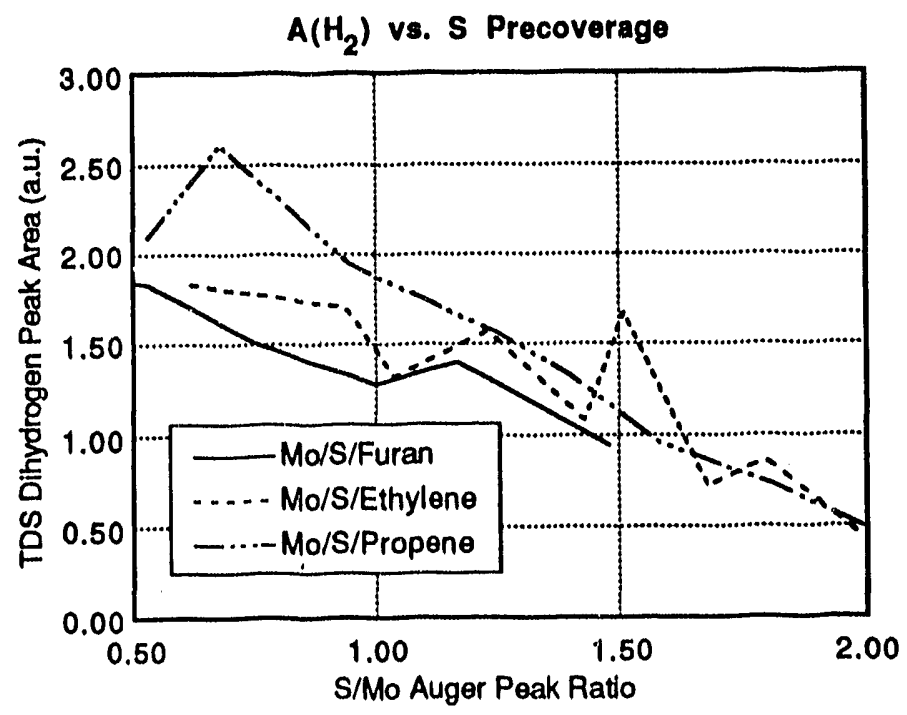

Figure 4. Total $H_{2}$ TPRS area as a function of sulfur precoverage 


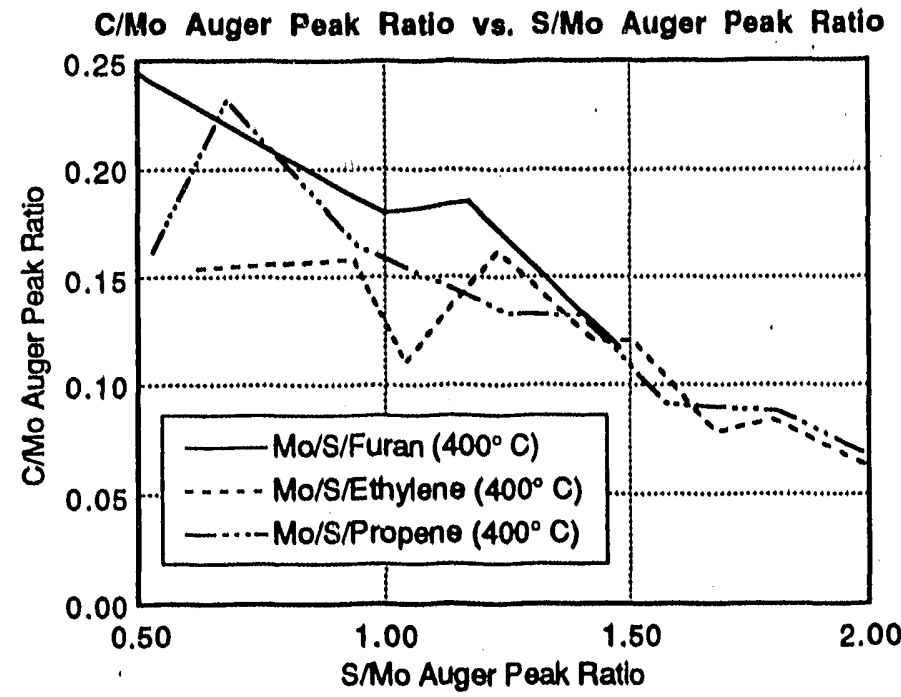

Figure 5. C.Mo AES ratio as a function of sulfur precoverage. (400C data)

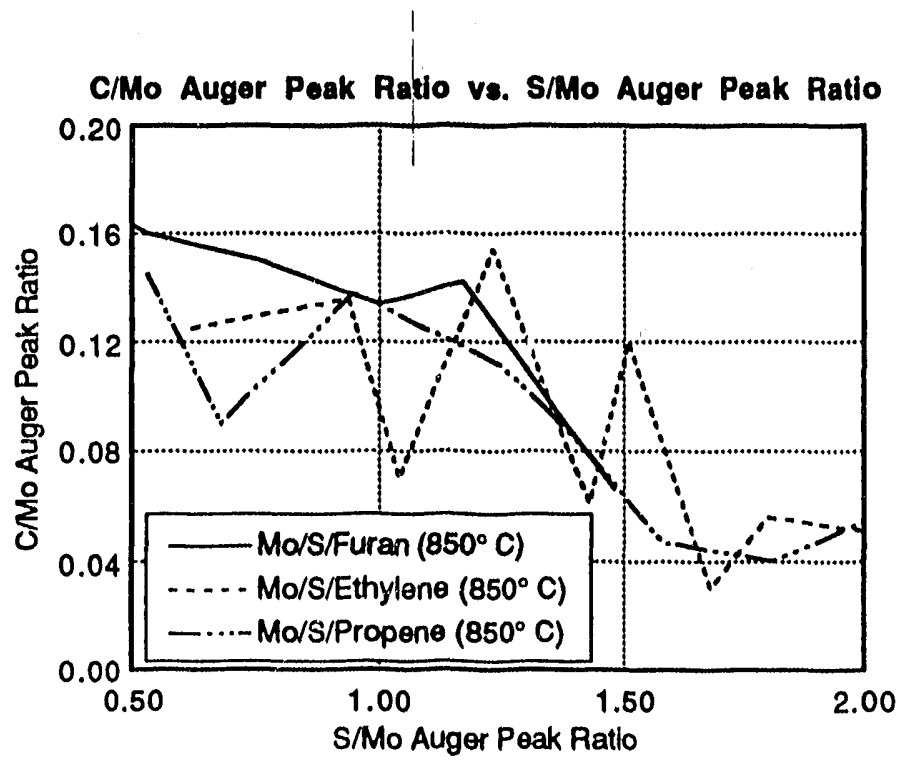

Figure 6. C/Mo AES ratio as a function of of sulfur precoverage ( $850 \mathrm{C}$ data). 

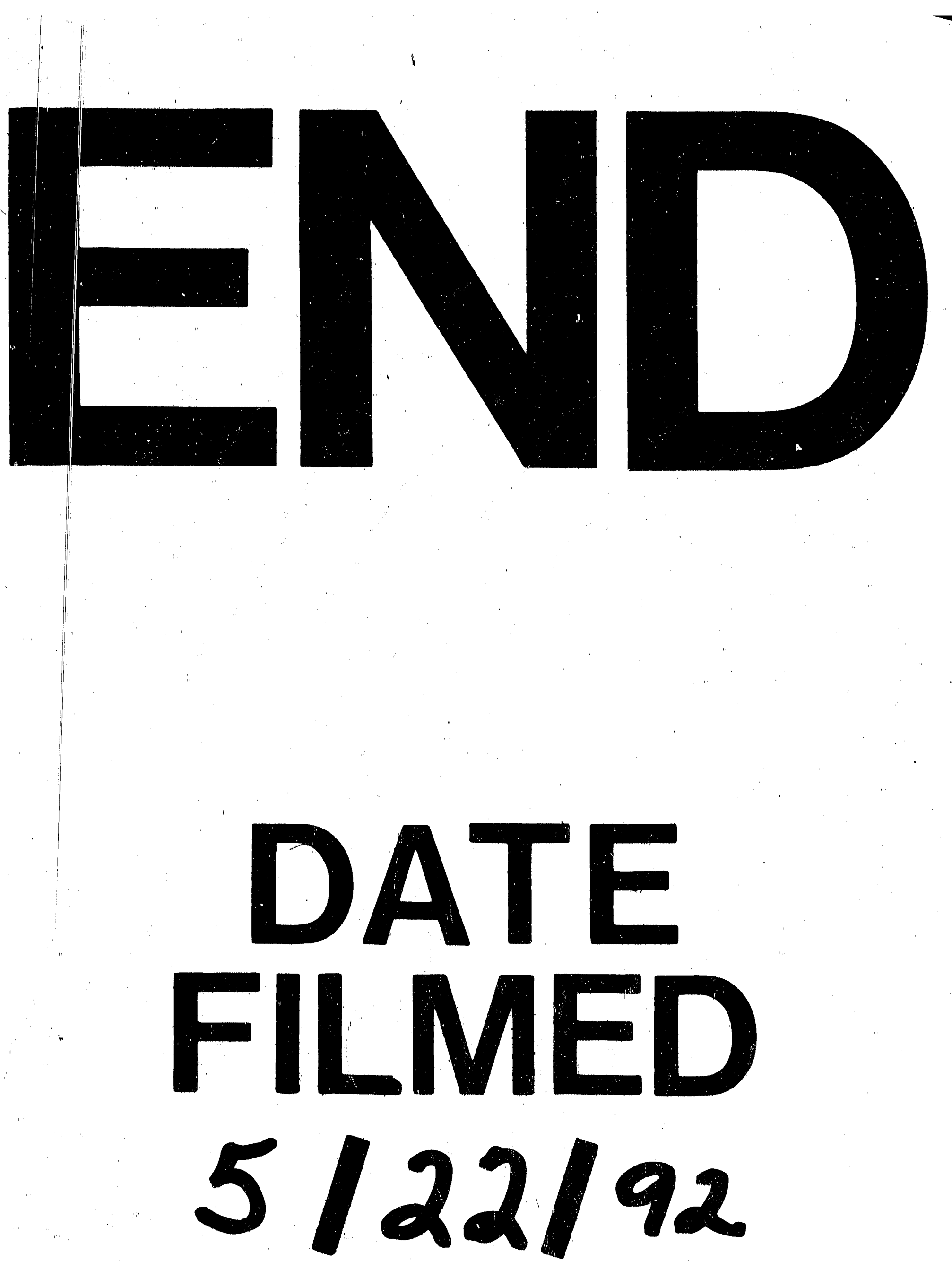
